\title{
Forecast of Power Grid Investment Scale Based on Support Vector Machine
}

\author{
Yongli Wang ${ }^{1}$, Yanchao $\mathrm{Lu}^{2}$, JingyanWang ${ }^{1}$, Xiaohui Wang ${ }^{2}$, Shuo Wang ${ }^{1}$, Lu Xue ${ }^{1}$ \\ ${ }^{1}$ Departments of Economics and Management, North China Electric Power University, Beijing 102200, China \\ ${ }^{2}$ State Grid Economic and Technological Research Institute Co., Ltd., Changping District, Beijing 102209, China
}

\begin{abstract}
Economic transformation creates a new environment for grid investment. In the situation of high quality development, the traditional investment scale prediction model is no longer applicable. Aiming at the problems of single parameter of grid-driven investment scale prediction model and poor linear fitting accuracy, a provincial medium- and long-term investment scale prediction model based on support vector machine was proposed. Aiming at the single parameter and poor line fitting accuracy of the grid-driven investment scale prediction model under the new situation, the new environment, new directions and new requirements for grid investment are analyzed. Based on the support vector machine algorithm, a mediumand long-term investment scale prediction model for provincial grids based on support vector machines is proposed. The scale of provincial grid investment is expected from 2019 to 2022 . The empirical results show that the prediction model constructed in this paper is effective and feasible. It is of great significance to explore the prediction model of medium and long-term investment scale of power grid enterprises in the new situation.
\end{abstract}

\section{Introduction}

With the continuous deepening of the new round of power system reform, the research's focus on investment management of power grid companies has shifted from investment efficiency, finanare the samplecing management, investment risk, to the direction of macro decision-making and precise investment. Taking the mid-to-long-term investment scale of grid companies as the research object, analyzing the investment environment is important [1-5].

The economic transformation has fostered a new environment for grid investment. China's economy has been shifted from a high-speed growth stage to a high-quality development stage. Quality change, efficiency change, and power change have become inevitable paths to promote economic development. Under the high-quality development situation, the traditional investment scale prediction model is no longer applicable. Therefore, it is of great research significance to explore the forecast model of medium and long-term investment scale of power grid enterprises under the new situation $[6,9]$.

The energy revolution is leading a new direction for grid investment. The strategy of energy production and consumption revolution (2016 2030) pointed out that China's energy development is entering from total volume expansion to quality improvement and efficiency improvement. In the new stage of transformation, clean and low-carbon development has become the general trend. In this context, a group of energy storage, distributed energy, and comprehensive energy, deeply integrate new industries and technologies of "Internet +" is booming $[8,10]$.

Institutional reform puts forward new requirements for investment. New round of electricity reform, transmission and distribution prices, service quality, and effective assets were affected. To strict supervision, the investment scale must be planned within the scope of growth [7].

\section{Index system}

\subsection{Grey relation theory}

Grey correlation analysis is often used to judge the degree of correlation between factors. The core is to compare the "grey correlation" among various factors. The specific calculation steps of the gray correlation degree are as follows:

Step 1: There are sequences of the same length and the initial values are not zero.

$$
\begin{gathered}
X_{0}=\left[X_{0}(1), \mathrm{X}_{0}(2), \cdots, \mathrm{X}_{0}(\mathrm{n})\right] \\
X_{i}=\left[X_{i}(1), \mathrm{X}_{i}(2), \cdots, \mathrm{X}_{i}(\mathrm{n})\right](\mathrm{i}=1,2, \cdots, 1) \\
X_{0} \text { is a reference sequence and } X_{i} \text { is a }
\end{gathered}
$$
comparison sequence. 
Step 2: Calculate the grey absolute correlation $\phi_{0 i} \backslash$

$$
\phi_{0 i}=\frac{1+\left|S_{0}\right|+\left|S_{i}\right|}{1+\left|S_{0}\right|+\left|S_{i}\right|+\left|S_{i}-S_{0}\right|}
$$

Step 3: calculate the gray relative correlation $\pi_{0 i}$

$$
\pi_{0 i}=\frac{1+\left|S_{0}^{\prime}\right|+\left|S_{i}^{\prime}\right|}{1+\left|S_{0}^{\prime}\right|+\left|S_{i}^{\prime}\right|+\left|S_{i}^{\prime}-S_{0}^{\prime}\right|}
$$

Step 4: Calculate the grey comprehensive correlation Calculated as follows:

$$
\rho_{0 i}=0.5 \times\left(\phi_{0 i}+\pi_{0 i}\right)
$$

\subsection{External drivers}

This paper sorts out the index system of external driving factor for power grid investment from four dimensions, namely power demand factor, power grid security factor, energy transition factor and technological innovation

\begin{tabular}{|c|c|}
\hline Indicator type & Index \\
\hline \multirow{3}{*}{ Power demand factors } & $\begin{array}{l}\text { Regional electricity } \\
\text { consumption }\end{array}$ \\
\hline & District electricity structure \\
\hline & Regional load demand \\
\hline \multirow{3}{*}{ Grid security factors } & Power supply reliability \\
\hline & $\begin{array}{c}\text { Comprehensive voltage } \\
\text { qualification rate }\end{array}$ \\
\hline & Capacity to load ratio \\
\hline \multirow{3}{*}{$\begin{array}{l}\text { Energy transition } \\
\text { factors }\end{array}$} & Regional electricity share \\
\hline & Renewable energy share \\
\hline & $\begin{array}{l}\text { Renewable energy } \\
\text { consumption rate }\end{array}$ \\
\hline \multirow{3}{*}{$\begin{array}{l}\text { Factors of } \\
\text { technological } \\
\text { innovation }\end{array}$} & Automation coverage \\
\hline & Smart meter coverage \\
\hline & $\begin{array}{c}\text { Proportion of smart } \\
\text { substations }\end{array}$ \\
\hline
\end{tabular}
factor.

Tab. 1. Indicators of external driving factors

Table 2 shows the calculation results of the grey correlation coefficient between the external driving factor indicators and investment sequence of the province's power grid investment.

Tab. 2. Grey correlation coefficients

\begin{tabular}{c|c|c}
\hline $\begin{array}{c}\text { Indicator } \\
\text { type }\end{array}$ & Index & $\begin{array}{c}\text { Correlation } \\
\text { coefficient }\end{array}$ \\
\hline \multirow{2}{*}{$\begin{array}{c}\text { Power } \\
\text { demand } \\
\text { factors }\end{array}$} & $\begin{array}{c}\text { Regional Electricity } \\
\text { Consumption }\end{array}$ & 0.79 \\
\cline { 2 - 3 } & $\begin{array}{c}\text { Proportion of } \\
\text { electricity used in } \\
\text { secondary production }\end{array}$ & 0.52 \\
\cline { 2 - 3 } Regional load demand & 0.51 \\
\hline $\begin{array}{c}\text { Grid } \\
\text { Security } \\
\text { Factors }\end{array}$ & $\begin{array}{c}\text { Power supply } \\
\text { reliability }\end{array}$ & 0.63 \\
\cline { 2 - 3 } & Comprehensive voltage & 0.63 \\
\hline
\end{tabular}

\begin{tabular}{c|c|c}
\hline \multirow{2}{*}{\begin{tabular}{c} 
Energy \\
\cline { 2 - 2 } $\begin{array}{c}\text { transition } \\
\text { factors }\end{array}$
\end{tabular}} & $\begin{array}{c}\text { Rapalification rate } \\
\text { Regional electricity } \\
\text { share }\end{array}$ & 0.52 \\
\cline { 2 - 3 } & $\begin{array}{c}\text { Renewable energy } \\
\text { share }\end{array}$ & 0.73 \\
\cline { 2 - 3 } & $\begin{array}{c}\text { Renewable energy } \\
\text { consumption rate }\end{array}$ & 0.57 \\
\hline
\end{tabular}

According to the grey correlation analysis results, the grey correlation coefficients of the province's external driving factor indicators and grid investment are relatively high and both greater than 0.5 , indicating that power demand factors, grid security factors, energy transition factors, and technological innovation factors are all external driving factors that affect grid investment.

\section{Model building}

\subsection{Support vector machines}

The basic principle is as follows:

$$
\begin{aligned}
& \left(x_{1}, y_{1}\right),\left(x_{2}, y_{2}\right), \ldots,\left(x_{k}, y_{k}\right) \\
& \in R^{N} \times R
\end{aligned}
$$

where $x_{i} \in R^{N}$ is the input paramet The growth rate ofer, $y_{i} \in R$ is the corresponding output parameter, and $k$ is the number of samples. The input parameters and output parameters can be expressed as:

$$
f(\mathrm{x})=\omega^{*} \theta(\mathrm{x})+b
$$

In the formula, $\omega$ is a weight vector and $b$ is a threshold.

The objective function and constraints are as follows:

$$
\begin{array}{r}
R(\omega)=\min \left[\frac{1}{2}\|\omega\|^{2}+C \sum_{i=1}^{n}\left(\xi_{i}+\xi_{i}^{*}\right)\right] \\
\text { s.t. }\left\{\begin{array}{l}
y_{i}-f\left(x_{i}\right) \leq \varepsilon+\xi_{i} \\
f\left(\mathrm{x}_{i}\right)-\mathrm{y}_{i} \leq \varepsilon+\xi_{i}^{*} \\
\xi_{i}, \xi_{i}^{*} \geq 0 \\
0 \leq i \leq 1
\end{array}\right.
\end{array}
$$

In the formula, $\xi_{i}$ and $\xi_{i}^{*}$ are non-negative relaxation variables; $C$ is a penalty factor, which controls the degree of punishment for samples that exceed the error range, and plays a role in balancing empirical risk and model complexity; $\varepsilon$ is an insensitive loss function parameter.

The Lagrangian method is used to solve the above optimization problem, as follows:

$$
W\left(\mathrm{a}_{i}, \mathrm{a}_{i}^{*}\right)=\max \left[\frac{1}{2} \sum_{i=1}^{n} \sum_{j=1}^{n}\left(\mathrm{a}_{i}-\mathrm{a}_{i}^{*}\right)\left(\mathrm{a}_{j}-\mathrm{a}_{j}^{*}\right) K\left(\mathrm{x}_{i}, \mathrm{x}_{j}\right)\right]
$$

The regression functions of SVM are as follows: 


$$
\begin{gathered}
f(\mathrm{x})=\sum_{i=1}^{n}\left(\mathrm{a}_{i}-\mathrm{a}_{i}^{*}\right) K\left(\mathrm{x}_{i}, \mathrm{x}_{j}\right)+b \\
K\left(\mathrm{x}_{i}, \mathrm{x}_{j}\right)=\exp \left(-\mathrm{g}\left|\mathrm{x}_{i}-\mathrm{x}_{j}\right|^{2}\right)
\end{gathered}
$$

\subsection{Case study}

By observing the historical data, although power consumption has been increasing from 2013 to 2018, grid investment has shown a downward trend and then an upward trend. This shows that there are still other factors affecting grid investment. Regional power consumption, power supply reliability, power share, automation coverage and grid investment data are used to build a predictive learning model. The data of each parameter from 2015 to 2018 are shown in Table 3.

Tab. 3. Parameter data from 2015 to 2018

\begin{tabular}{c|c|c|c|c}
\hline Years & 2015 & 2016 & 2017 & 2018 \\
\hline $\begin{array}{c}\text { Grid investment } \\
(100 \text { million yuan) }\end{array}$ & 380 & 300 & 270 & 340 \\
\hline $\begin{array}{c}\text { Electricity } \\
\text { consumption } \\
\text { (billion kWh) }\end{array}$ & 3550 & 3870 & 4190 & 5485 \\
\hline $\begin{array}{c}\text { Power supply } \\
\text { reliability (\%) }\end{array}$ & 99.94 & 99.98 & 99.97 & 99.96 \\
\hline Electricity ratio (\%) & 15.57 & 19.34 & 24.00 & 33.00 \\
\hline $\begin{array}{c}\text { Automation } \\
\text { coverage (\%) }\end{array}$ & 26.6 & 59.5 & 62.1 & 90.0 \\
\hline
\end{tabular}

Based on historical data, the predicted values of each parameter from 2019 to 2020 are taken from the target value of the 3-year action plan for the company to promote high-quality development in the province. The data are shown in Table 4.

Tab. 4. Parameter data from 2019 to 2020

\begin{tabular}{|c|c|c|}
\hline Years & 2019 & 2020 \\
\hline $\begin{array}{c}\text { Electricity consumption (billion } \\
\text { kWh) }\end{array}$ & 4755 & 4995 \\
\hline Power supply reliability (\%) & 99.98 & 99.99 \\
\hline Electricity ratio (\%) & 34 & 35 \\
\hline Automation coverage (\%) & 95 & 97 \\
\hline
\end{tabular}

On this basis, three scenarios are used to forecast the province's grid investment demand from 2021 to 2022. The data of each indicator from 2021 to 2022 are shown in Table 5.

Scene 1: Electricity is growing slowly, and investment motivation is mainly due to the renewal of existing assets and the continuous improvement of the level of power grid equipment.

The growth rate of electricity consumption is calculated at an average growth rate of $5 \%$, and the reliability of power supply remains unchanged, and the electricity replacement and automation coverage rates have slightly increased.
Scene 2: The current growth rate of electricity is maintained, and changes in the external environment accelerate the requirements for grid construction and promote the speed of asset renewal.

The growth rate is calculated based on the average growth rate of $6 \%$, and the reliability of power supply, energy substitution and automation coverage have slightly increased.

Scene 3: High-speed power growth, high-quality development places higher requirements on power grid construction, and investment needs increase.

Tab. 5. Parameter data from 2021 to 2022

\begin{tabular}{|c|c|c|c|c|c|}
\hline Scene & Years & $\begin{array}{c}\text { Electricit } \\
\text { consumpt } \\
\text { ion } \\
\text { (billion } \\
\mathrm{kWh})\end{array}$ & $\begin{array}{c}\text { Power } \\
\text { supply } \\
\text { reliabilit } \\
\mathrm{y}(\%)\end{array}$ & $\begin{array}{c}\text { Electrici } \\
\text { ty ratio } \\
(\%)\end{array}$ & $\begin{array}{c}\text { Automati } \\
\text { on } \\
\text { coverage } \\
(\%)\end{array}$ \\
\hline $\begin{array}{c}\text { Scene } \\
1\end{array}$ & 2021 & 5244.75 & 99.991 & 36 & 97.5 \\
\cline { 2 - 6 } & 2022 & 5506.98 & 99.991 & 37 & 98 \\
\hline $\begin{array}{c}\text { Scene } \\
2\end{array}$ & 2021 & 5294.7 & 99.993 & 37 & 98 \\
\hline $\begin{array}{c}\text { Scene } \\
3\end{array}$ & 2022 & 5612.38 & 99.993 & 39 & 99 \\
\cline { 2 - 6 } & 2022 & 5344.65 & 99.995 & 38 & 98.5 \\
\hline
\end{tabular}

According to the support vector machine algorithm, the province's investment demand forecast for 2019-2022 is shown in Table 7. It can be known from the prediction model that the forecast value of investment demand in the province in 2019 is 35.05 billion yuan, and the forecast value in 2020 is 34.99 billion yuan, and the forecast value in 2021 is 343.4 to 34.977 billion yuan, and the forecast value in 2022 is 340.2 to 347.9 billion yuan.

Tab. 6. Forecast of grid investment scale

\begin{tabular}{|c|c|c|}
\hline \multirow{2}{*}{ Scene } & Years & $\begin{array}{c}\text { Investment demand } \\
(100 \text { million yuan })\end{array}$ \\
\hline \multirow{2}{*}{ No scene } & 2019 & 350.6 \\
\cline { 2 - 3 } & 2020 & 350.1 \\
\hline \multirow{2}{*}{ Scene1 } & 2021 & 343.6 \\
\cline { 2 - 3 } & 2022 & 340.5 \\
\hline \multirow{2}{*}{ Scene2 } & 2021 & 347.2 \\
\cline { 2 - 3 } & 2022 & 346.8 \\
\hline \multirow{2}{*}{ Scene3 } & 2021 & 349.6 \\
\cline { 2 - 3 } & 2022 & 347.8 \\
\hline
\end{tabular}

\section{Conclusion}

This article provides a new modelling idea for the research object of mid-to-long-term investment scale of power grid companies. A power grid investment scale prediction model was constructed and the following conclusions were obtained through empirical analysis:

(1) This paper analyzes the external environment of power grid investment. Under the new situation of high-quality development, economic transformation has given birth to Grid companies invest in a new environment, the energy revolution and service transformation have led a new direction in investment, and institutional reforms have put forward new investment requirements. 
(2) This paper explores the index system of external driving factors for grid investment. From the aspects of power demand, grid security, energy transition, and technological innovation, the key driving factors are selected based on the grey correlation theory, including capacity, regional power share, power supply reliability and automation coverage.

(3) This paper builds a medium- and long-term investment scale prediction model for provincial power grids, and uses support vector machine algorithms to predict the investment scale of a provincial power grid in China in 2019-2022. The model has good precision, can provide long-term investment in the provincial grid power grid a useful reference.

\section{Acknowledgement}

This article is supported by "State Grid Technology Project” (Grant No: SGJSJY00JJJS1800086).

\section{References}

1. Zhao Yonggang. Research on Financial Intensive Management Mode of Power Grid Enterprises [J]. China International Finance, 2017, (23): 265-266.

2. Yang Qi. Research on Financing Problems of Power Grid Enterprises. Contemporary economy, 2013 (22): 11-13.

3. Sun Yihan. Research on Decision-making Methods for Grid Planning and Investment Optimization under the Background of Electric Power System Reform. [D]. North China Electric Power University. Beijing: 2017.

4. Ren Baoping. China's high-quality development goals and requirements [J]. Red flag manuscript, 2018, (24): 21-23.

5. $\mathrm{Xu}$ Xiaomin. Research on Optimal Investment Decision of Complex Power Grid Based on Power Demand and Investment Capability. [D]. North China Electric Power University. Beijing: 2017.

6. Guo Huichao. Research on Constructing Decision Model of Power Grid Investment Scale Using System Dynamics Tools [J]. Contemporary economy, 2017 (24): 97-99.

7. Li Shan. Research on Reference Grid Modeling and Optimization Methods. [D]. Shan Dong University. Jinan: 2017.

8. Zhao Huiru, Fu liwen. Quantitative Research on Investment Capability of Power Grid Enterprises [J]. Hydropower Energy Science,2012 (4): 191-194.

9. Chen, Yi., et al., Research on the Maximum Investment Capability of Power Grid in the Reform of Transmission and Distribution Price[J]. Hydropower Energy Science,2017 (12): 212-216.

10. Yang Min., et al., Analysis of Economic Power Relationship and Demand Forecast in the New Normal[J]. Smart Power,2018 (46): 50-56. 